\title{
The present situation and the future of air preheater in power
}

\author{
Luping Liu, Longsheng Zou
}

Chongqing water resources and electric engineering college, Chongqing 402160, China;

Keywords: air preheater,flue gas, waste heat resources, $3 \mathrm{~d}$ inside/outside tube.

\begin{abstract}
This paper analyzed source and proportion of waste heat resources in power, and expounded characteristics and utilization way. It also indicated of rotary air preheater in the advantage position of waste heat utilization, but was some shortage. Finned heat transfer was enhanced a development direction, and $3 \mathrm{~d}$ inside/outside tube air preheater of heat transfer enhancement was an outstanding samples. This paper focused on $3 \mathrm{~d}$ inside/outside tube air preheater thermodynamic properties, and pointed out some advantages in the aspect of heat transfer. Through analysis found that it was the key equipment after flue gas waste heat utilization.
\end{abstract}

\section{Introduction}

\subsection{The source of waste heat resource}

In recent years, the haze appeared frequently in winter of 2015.Scientific workers researched various data, found that coal was the main source of pollutants, it contributed $61 \%$ of the share of PM2.5[1].Power plants consumed 50\% coal of total output, was burning in the boiler. Boiler energy loss was mainly composed of smoke exhaust losses, loss of mechanical incomplete combustion, ash physical losses, chemical of incomplete combustion loss, heat loss. Practice proved that the smoke exhaust heat loss was the largest one heat loss, accounting for $80 \%$ or higher, figure 1 pointed out the distribution state of boiler heat loss.

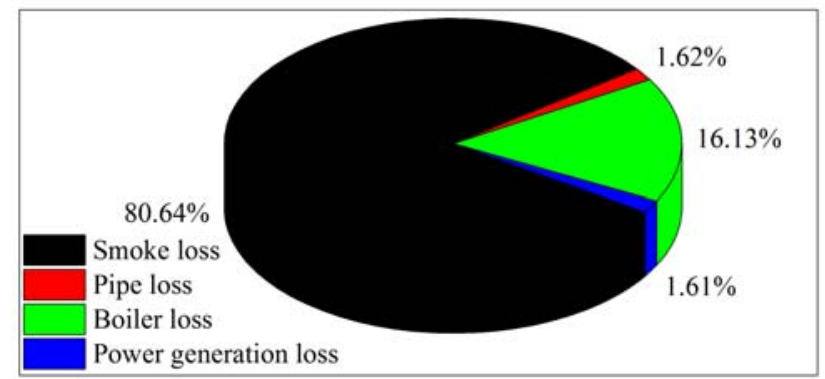

Fig.1 Boiler energy loss

Smoke heat loss was main factors affecting the temperature. Under normal circumstances, the exhaust temperature rise every $10^{\circ} \mathrm{C}$, exhaust heat loss increased by $0.6 \% \sim 1.0 \%$, and power generation coal consumption increase about $2 \mathrm{~g} / \mathrm{kW} \mathrm{h}$. At present, operation of thermal power unit, boiler exhaust smoke temperature was generally at around $125 \sim 150^{\circ} \mathrm{C}$, lignite boiler had reached around $170^{\circ} \mathrm{C}$ for even. High exhaust temperature of the boiler was a common phenomenon, resulting in huge energy loss[2]. Power plants was not only to the pursuit of economic benefits, also wanted to obtain great social benefits. Thus improved the thermal efficiency, improved thermal efficiency of power plants, not only could reduce the cost of power generation and consumption of fossil energy, direct cut in emissions of pollutants, was conducive to the protection of resources and environment, and realized the sustainable development of the society.

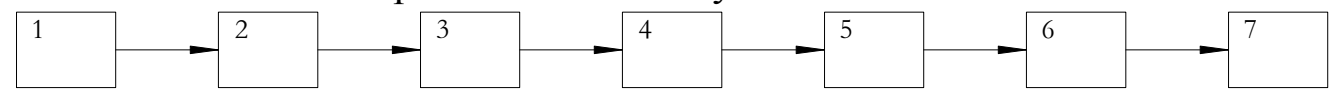

Fig.2 Boiler smoke extraction process

1--Chamber of furnace smoke; 2--Denitration process; 3--Electrostatic dust removal;

4--Air preheater; 5--Induced draft fan; 6--The desulfurization process;7--The chimney smoke

As could be seen from the figure 2, flue gas went into chimney before going through denitration, electric, air preheater heat transfer and desulfurization of four important step. Flue gas after heat 
exchange through air preheater, and greatly lowered its temperature, might be lower than $80^{\circ}$ C.Flue gas waste heat recovery processes running results showed that the best desulfurization efficiency in order to make smoke temperature, reduced the water consumption of desulfurizer, desulfurization tower entrance smoke temperature down to about $85^{\circ} \mathrm{C}$ was suitable.

\subsection{The characteristics of waste heat resource}

Waste heat resources while sources diversification, temperature change was big, style diversity, but they also had a grade. According to waste heat resource temperature could be divided into three broad categories:(1) High temperature waste heat resources, above $500^{\circ} \mathrm{C}$, most of these resources from industrial furnaces, such as melting furnace, heating furnace, cement kiln and incinerator. (2) Medium temperature waste heat resources, $200-500^{\circ} \mathrm{C}$, such as various equipment exhaust gas of power plant and some furnaces.(3) Low temperature waste heat resources, below $200^{\circ} \mathrm{C}$ of flue gas and liquid was below $100^{\circ} \mathrm{C}$.

Recovery methods of waste heat were more, and often divided into two major categories of heat recovery and dynamic recovery. The basic principle of recycling waste heat resources had four aspects:(1) High temperature flue gas priority should be given by oneself system;(2) Waste heat could be used in the production of steam or hot water, etc;(3) Enterprise needed to make a comprehensive thermal efficiency and economic feasibility analysis; (4) Requirements must be recycled waste heat resources, could make the corresponding industry standards.

But according to analysis in situation of waste heat resource utilization there were three aspects:1) Waste heat resource was cycles, discontinuity, and caused of waste heat utilization way prone to volatility, adverse consequences;2) Part of waste heat resource containing impurities properties, such as power plants produced smoke contains a lot of dust, and corrosive substance, such as $\mathrm{SO} 2.3$ ) Waste heat utilization of equipment and devices, and easily being limited by the production area, production conditions, etc.

\section{The present situation of air preheater}

\subsection{The rotary air preheater}

Waste heat boiler using the most common way was by adding air preheater, this was a method of indirect recovery of waste heat. Able to take advantage of flue gas heat equipment include: rotary air preheater and tubular air preheater. Rotary air preheater was divided into juncker type air preheater and flue gas/GGH heat exchanger, the wind bell type air preheater. It was mainly used in large units, and tubular air preheater was mainly used in dozens of small mw unit[3].80-90's of the 20th century, FGD process was gradually into the thermal power industry of our country. Early FGD process operation, some experts thought the flue gas after the GGH heat, smoke temperature was high, could reduce after desulfurization of flue gas to the downstream equipment corrosion. But because after GGH heat of flue gas, flue gas temperature was still lower than the dew point temperature of sulfuric acid could result in acid condensation in the subsequent equipment. Not only that, due to the increasing with temperature of liquid corrosion increases greatly, high temperature smoke more aggravate corrosion tendency of condensation water, make flue gas after GGH heat had stronger corrosion resistance.

Now commonly used was the rotary air preheater, its advantages in the following respects:(1) Rotary air preheater due to the heat transfer surface density up to $500 \mathrm{~m} 2 / \mathrm{m} 3$, so the structure was compact, cover an area of an area small, its size was about the same volume of 1/10 of the tubular air preheater.(2) Quality was light, because of the tubular air preheater tube wall thickness was $1.5 \mathrm{~mm}$, and the rotary air preheater heat storage plate thickness of $0.5-1.25 \mathrm{~mm}$, however, and the heat storage plate was very compact, so the metal consumption of the rotary air preheater with capacity of about $1 / 3$ of the tubular air preheater.(3)Rotary air preheater flexible layout, make boiler body was easy to get reasonable layout scheme.(4)Under the same external conditions, the rotary air preheater for the heating surface metal temperature was higher, so the risk of low temperature corrosion was lighter tubular air preheater. 


\subsection{The shortage of rotary air preheater}

Power plants was usually used in heating juncker type air preheater.Juncker type air preheater could be divided into binary warehouse and three points warehouse two kinds, composed of cylindrical rotor and fixed cylindrical shell, smoke duct and the composition of transmission device. Heating surface was installed on the rotating rotor, the rotor was divided into several fan-shaped warehouse, every warehouse, it was full of heat storage plate made of corrugated metal sheet. The top and bottom of the cylindrical shell corresponding to the up and down, separated into the flue gas circulation area, air flow area and sealing area three parts. The problem but juncker type air preheater was low temperature corrosion and air leakage.

\subsubsection{Low temperature corrosion}

Reason was due to the low temperature corrosion in air preheater pulverized coal containing sulfur content, would be generated in the combustion process of $\mathrm{SO}_{2}$ and $\mathrm{SO}_{3}$. When the flue gas temperature was below $200^{\circ} \mathrm{C}$, too low $\mathrm{SO}_{3}$ sulfuric acid would combine with water vapor generated steam, namely:

$$
\begin{aligned}
& \mathrm{SO}_{2}(G)+\mathrm{H}_{2} \mathrm{O}(\mathrm{G})=\mathrm{H}_{2} \mathrm{SO}_{3}(G) \text { Weak-acid } \\
& \mathrm{H}_{2} \mathrm{SO}_{3}(\mathrm{~L}) \rightarrow 2 \mathrm{H}^{+}+\mathrm{SO}_{3}^{2-} \\
& \mathrm{SO}_{3}(\mathrm{G})+\mathrm{H}_{2} \mathrm{O}(\mathrm{G})=\mathrm{H}_{2} \mathrm{SO}_{4}(G) \text { Strong-acid } \\
& \mathrm{H}_{2} \mathrm{SO}_{4}(\mathrm{~L}) \rightarrow 2 \mathrm{H}^{+}+\mathrm{SO}_{4}^{2-}
\end{aligned}
$$

Sulfuric acid was much taller than water vapour condensation of steam temperature, sometimes could reach $140-160^{\circ} \mathrm{C}$, therefore contain only a small amount of sulfuric acid vapor in flue gas, flue gas dew point temperature would rise significantly. When the flue gas into the low temperature heating surface, because of the smoke temperature decreased or came into contact with the heating surface of low temperature, as long as the temperature was lower than the dew point temperature, water vapor and sulfuric acid vapor would condense. Once the steam was condensed on the heating surface of sulfuric acid would make the metal produces serious acid corrosion. Strong corrosion usually occured at low temperature in the cold end of the air preheater, because in the air and flue gas temperature. Low temperature corrosion of metal tube type heat exchanger was broken, and made a lot of air leakage into the flue gas, worsened the air combustion, boiler efficiency was reduced. Corrosion at the same time also could aggravate the dust, smoke duct resistance increase, affected the boiler safe and economic operation. The factors of influencing low temperature corrosion was: sulfuric acid vapor condensation quantity, the greater the amount of condensation, the more serious corrosion. Practice showed that the most serious corrosion area had two, namely occurring near the wall of the warm water dew point; another 20 to $45^{\circ} \mathrm{C}$ below the dew point of flue gas.

Low temperature corrosion measure, would be pre desulfurization of coal processing. Huang Tie sulfur in coal could be in the coal pulverizing system, the use of power equipment to isolate it. Low oxygen combustion, i.e., lower excess air coefficient in the combustion process, thus reducing the residual oxygen in flue gas, to reduce the amount of $\mathrm{SO} 2$ was converted into $\mathrm{SO} 3$. In addition, put an end to the boiler air leakage were also effective measures to reduce the residual oxygen in flue gas. Also could improve the equipment material, deal with the low temperature corrosion. American scientists had discovered that adding $\mathrm{Cu}$ metal corrosion resistant steel, it was significant for the sulfuric acid dew point corrosion resistant effect. Japan in 1960, on the basis of atmospheric corrosion resistant steel, further analysis of alloy elements on the properties of sulfuric acid dew point corrosion effect, and then developed the high grade corrosion resistant steel. In our country developed using steel containing $\mathrm{Cu}$ with $\mathrm{Sb}$ of ND steel, its acid corrosion effect was good, could slow down the corrosion rate, prolong the service life of equipment, compared with other corrosion resistant steel had a certain advantage[4].

\subsubsection{The air leakage of air preheater}

Rotary air preheater leakage air volume was big, in good condition was $8 \%-10 \%, 20 \%$ to $30 \%$ when sealed. At the same time, its structure was complex, high manufacturing process requirements, operation maintenance, repair and complex. Carry air leakage and seal air leakage was the cause of 
air leakage in air preheater, due to the increase in leakage air volume will make send, induced draft fan power consumption increases, increased exhaust heat loss, the boiler efficiency lower. If air leakage was too large, would cause the furnace air flow was insufficient, and the influence, might cause slag boiler.

\section{3. $3 \mathrm{~d}$ inside/outside tube characteristics of ribbed tube air preheater}

Improved the heat transfer enhancement of heat transfer technology, strengthened heat transfer technology could be divided into two types: passive and active technology. Passive technology referred to besides conveying power consumption of heat transfer medium, no longer needed additional power technology, active technology was the need to use extra power[5].

Rib was a kind of passive heat transfer enhancement technology, it had the expansion of the large area, also could produce disturbance. Ribbed reinforced heat transfer effect was more significant, in the compact heat exchanger finned tube had been widely used. $3 \mathrm{~d}$ rib tube was a new type of heat transfer enhancement tube/lateral element, its thermal performance was excellent, widely used in the manufacture of all kinds of heat exchanger.

Mechanism of $3 \mathrm{~d}$ heat transfer tube, medium after through the wings high needle rib form karman vortex street flow state. The flow to promote the turbulence of the fluid, the direction of the acceleration was parallel to the thermal boundary layer, reduced the thickness of boundary layer, thus to strengthen the tube without phase change heat transfer. At the same time because of the liquid in the finned surface tension decreases, and the liquid channel was easy, liquid film thickness thinning, which strengthened the condensation heat transfer. $3 \mathrm{~d}$ rib tube could solve a lot of difficulties of heat transfer enhancement tube, mathematical model of heat transfer enhancement was ideal tube rib ratio could be as high as 6 above, figure 3 was a common 3 d inside/outside of tube structure schematic[5].

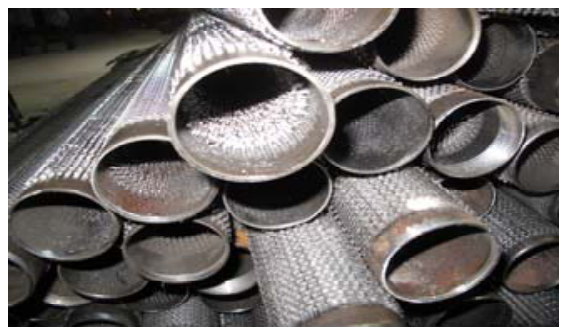

Fig.3 3 d inside/outside rib tube schematic diagram

Its practice showed that $3 \mathrm{~d}$ rib tube heat transfer enhancement had good effect and thermal performance, the convective heat transfer coefficient of the single phase fluid could reach 2.5-6 times of the light pipe, boiling heat transfer coefficient can be up to 2-5 times of the light pipe, condensation heat transfer coefficient of the light tube for 3 to 5 times. The prominent characteristics of $3 \mathrm{~d}$ rib tube are: (1) to reduce the volume and weight of the equipment;(2) improving the heat exchange equipment capacity, achieve high efficiency, energy saving;(3) the equipment working under low temperature difference, making full use of low grade energy, reducing emissions of thermal pollution;(4) $3 \mathrm{~d}$ finned tube had variability, through the design of improvement could make the heat pipe working medium to achieve the best match.

According to $3 \mathrm{~d}$ rib tube strengthening inside/outside heat exchange process made the tube box air flue gas heat exchanger. It could guarantee that the tube wall temperature was not lower than acid dew point temperature, the traditional tube heat exchanger tube wall temperature could not adjust, poor corrosion resistance. It could also improve the design to adjust tube wall temperature, avoided acid dew point area, in order to prolong the service life of the pipe. In three dimensions at present, $3 \mathrm{~d}$ inside/outside components manufacturing heat exchanger, tube had been applied in the breakthrough, and entered into power plant, petrochemical plant, and other fields[6-8].

\section{Summary}

According to the characteristics of the power plant waste heat resources, this paper expounded the operation of the rotary air preheater technology, pointed out its position in the practical application, 
but due to design flaws in itself has some deficiencies. This paper expounded $3 \mathrm{~d}$ inside/outside rib tube air preheater of thermodynamics characteristics and advantages, and confirmed by examples. Analysis found that the $3 \mathrm{~d}$ inside/outside air preheater power industry in the future was an important direction of development of heat exchange equipment.

\section{References}

[1] LI Biao. Environmental protection: coal was immediate cause of haze, contribution rate of $61 \%$ [EB]. China Taiwan Network. 2015-12-15, http : // news. china. com. Cn / live / 2015-12 /15/content _34818939. htm

[2] CHEN Song-feng, YANG Shu-bo. Reform of the boiler economizer energy saving efficiency[J]. Forestry Machinery and Civil Equipment, 2004, 32(6):41.

[3] JIE Hai-long, DIN Le-qun, JIANG An-zhong, etc. The analysis and comparison of power plant boiler heat recovery way[J]. Boiler Technology, 1995, (4):15-19.

[4] ZHENG De-sheng, YU Hong-tao. Smoke waste heat boiler using high level depth discussion[J]. Urban Construction Theory Research (Electronic version) 2013, (20):1-8.

[5] ZHANG Ya. Air in different rib arrangement $3 \mathrm{~d}$ rib tube thermal performance of the research [D]. Chongqing University, 2003.

[6] ZHAI Qiang, LIU Fan, HUANG Dan-qing, etc. 3 d rib inside and outside the pipe heat transfer components in the application of box type air preheater[C]. 2012, 1-5.

[7] ZHAO Zhi-jun, FENG Wei-zhong, ZHANG Ling, etc. Power plant boiler smoke waste heat recovery of theoretical analysis and engineering practice[J]. Power Engineering, 2009, 29(11): 994-997.

[8] ZHANG Qing-wu. $3 \mathrm{~d}$ rib tube heat exchange equipment in the application of petrochemical installations[J]. Petrochemical Equipment, 2009, 38(3): 84-86. 